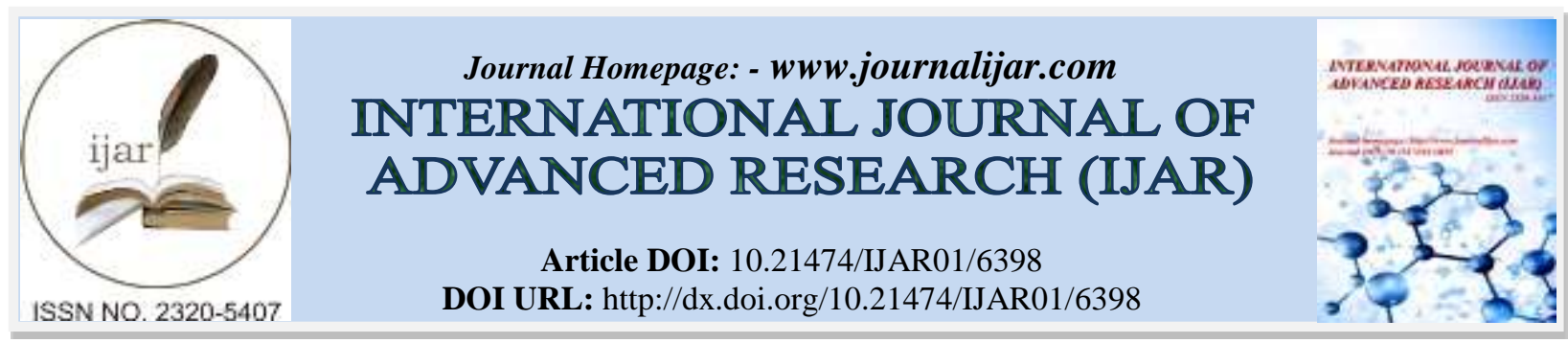

RESEARCH ARTICLE

\title{
"AN EXPERIMENTAL STUDY TO EVALUATE THE EFFECTIVENESS OF STRUCTURED TEACHING PROGRAMME ON SUICIDAL PREVENTION AMONG ANM STUDENTS AT ROYAL INSTITUTE OF NURSING, JAITO SARJA, BATALA, GURDASPUR, PUNJAB."
}

Ms. Rintu Chaturvedi.

Principal Royal Institute of Nursing, Jaito Sarja, Batala 143505, India.

\section{Manuscript Info}

Manuscript History

Received: 24 November 2017

Final Accepted: 26 December 2017

Published: January 2018

Key words:-

Evaluate, Effectiveness, Structured

Teaching Programme, Suicidal

Prevention.

\section{Abstract}

An experimental study was conducted to evaluate the effectiveness of structured teaching programme on suicidal prevention among ANM students in Royal Institute of Nursing, Jaito Sarja. The research design used in this study was one group pretest-posttest design. Total 50 A.N.M students were selected by convenient sampling. The tool used for study was self-structured questionnaire. Major findings of the study revealed that in pre-test, majority $31(62.0 \%)$ of them had inadequate knowledge, 19 (38.0\%) had moderately adequate knowledge and none of them had adequate knowledge where as in post-test majority 29 $(58.0 \%)$ of them had adequate knowledge, whereas $21(42.0 \%)$ of them had moderately adequate knowledge and none of them had inadequate knowledge. Post test score was greater than pretest score hence, research hypothesis $\left(\mathrm{H}_{1}\right)$ was accepted. The association between the post-test knowledge and demographic variables such as age, occupation of parents were found to be statistically significant and religion, domiciliary area, type of family, Education of parents, source of information, annual family income, source of income, any history of suicide in family and family history of mental illness were found to be statistically non-significant.

Copy Right, IJAR, 2018,. All rights reserved.

\section{Introduction:-}

Suicide is derived from a Latin word 'sui caedere' which means to kill oneself, suicide is also known as completed suicide is "act of taking one's own life". According to WHO, annual estimate approximately one million people die from suicide every year and for every 10 to 20 minute more people attempt to suicide worldwide. This represents one death for every 3 seconds on average. ${ }^{1}$

Sign and symptoms of suicide for all age group are : having trouble concentrating or thinking clearly, giving away belongings, suddenly changing, losing interest in activity they used to enjoy, performing self-destructive activities, isolating from friends, suddenly having trouble in schooling or at work place, expressing verbally about feeling hopelessness and guilty, change in pattern of sleep and eating habits, arranging ways to take their own life ${ }^{2}$ "Vijayakumar" in an editorial expresses the urgent need for suicide prevention in India and stresses that suicide is a multifaceted problem and hence suicide prevention programs should also be multidimensional. Collaboration, coordination, cooperation and commitment are needed to develop and implement a national plan, which is costeffective, appropriate and relevant to the needs of the community. In India, suicide prevention is more of a social 
and public health concern than a traditional exercise in the mental health sector. He concludes by saying that the time is ripe for mental health professionals to adopt proactive and leadership roles in suicide prevention and save the lives of thousands of young Indians. ${ }^{3}$

\section{Need Of Study:-}

According to WHO estimation, in the year 2014, approximately one million people died by committing suicide, and $10-20$ times more people attempted suicide worldwide. This represents one death in every 40 seconds and one attempt for every 3 seconds, on an average. The numbers of suicides are increasing in India. India accounts for 10\% of world's suicides. According to the latest national crime record bureau report, there are over 1.2 lakh suicides in 2006 and 1.3 lakh in 2007. It also states that Bangalore has the highest rate of suicides in India. ${ }^{4}$

Investigator noticed that the suicide rates are increasing day by day, because of terrain life of human being in the competitive world. The general populations are facing lots of physical, psychological, and social problems. Because of the lacuna in dealing with stressful situation, the people prefer suicide as easy escape for their problems. The high suicide rates emphasize the need to recognize suicide as a major health problem with an urgent need for intervention. It is possible for the nurse to import the knowledge on recognition of the emotional needs of people at different age group and warning signs of suicide demonstration by them to the common public community mental health programme, after proper assessment of their existing knowledge on the area, which can have a great influence in the prevention of suicide in our country.

Statement Of The Problem:-

"An experimental study to evaluate the effectiveness of structured teaching programme on suicidal prevention among ANM students at Royal Institute of Nursing, Jaito Sarja, Batala Gurdaspur, Punjab."

\section{Objectives:-}

\section{The objectives of study are:-}

1. To evaluate the pre-test knowledge regarding suicidal prevention among ANM students.

2. To evaluate the post-test knowledge regarding suicidal prevention among ANM students.

3. To compare pre-test and post-test knowledge regarding suicidal prevention among ANM students.

4. To find association between post-test knowledge with their selected demographic variables.

\section{Hypothesis:-}

$\mathrm{H}_{1}$ : There will be significant difference in knowledge of ANM students after STP on suicidal prevention.

$\mathrm{H}_{2}$ : There will be significant association of post-test knowledge with selected socio demographical variables of ANM students.

\section{Delimitation:-}

Study will be delimited to:

1. The students studying in A.N.M.

2. Anm students who are willing to participate in the study.

\section{Material And Method:-}

The research design used in this study was one group pretest-posttest design. Total 50 A.N.M students were selected by convenient sampling. The tool used for study was self-structured questionnaire. Part A consist 10 questions related to socio demographic variables such as Age, Religion, Domiciliary, Type of family, Education status of student, Occupation Of Parents, Annual Family Income, Source of information ,Any history of suicide in the family, Family history of mental illness. Part 2 consist of self-structured questionnaire of 30 multiple choice questions. The selected aspects are:- definition, incidence, causes, risk factors, methods, symptoms, warning signs ,diagnosis, management and prevention of suicide. Content validity was done by seven experts which includes experts in the field of community health nursing, child health nursing, psychiatric nursing, and Medical surgical Nursing. The reliability coefficient of scale was found to be 0.9 ; hence, the tool was highly reliable. 


\section{Result and Findings:-}

Findings related to demographic variables:-

It was found that majority $46(92.0 \%)$ of them belonged to age group of 18-23 years, $4(8.0 \%)$ of them belonged to age group of 24-29 years and none of them belonged to age group of 30-35 years. majority $28(56.0 \%)$ of them were Sikh, $21(42.0 \%)$ of them were Hindu, $1(2.0 \%)$ of them were Christian and none of them were Muslim. Their domiciliary area demonstrate that maximum number of students $39(78.0 \%)$ resided in rural area and $11(22.0 \%)$ of them resided in urban area. Type of family showed that most of them $46(92.0 \%)$ belonged to nuclear family, $4(8.0 \%)$ of them belonged to joint family and none of them belonged to the extended family. The educational status depicted that majority $27(54 \%)$ of the students were graduates, $15(30.0 \%)$ of them studied up to senior secondary and $8(16.0 \%)$ of them studied other courses before joining ANM. The occupation of their parents depicted that most of them $33(66.0 \%)$ were unemployed, 12(24.0\%) of them were self-employed, $5(10.0 \%)$ of them were professionals. Their source of information revealed that majority $34(68.0 \%)$ of them preferred watching T.V, $11(22.0 \%)$ of them used internet and $5(10.0 \%)$ were having newspaper as their source of information. Maximum number of students 45 (90.0\%) had family monthly income below Rs.5000, 4(8.0\%) of them had monthly income between Rs.5001-10000, and 1(2.0\%) of them had income between Rs.10001-15000.There were no history of suicide and mental illness in the family.

Findings related to pre-test and post-test knowledge of ANM students regarding suicidal prevention. (N=50)

\begin{tabular}{|l|c|c|c|c|}
\hline \multicolumn{2}{|c|}{ Pre-test } & \multicolumn{2}{c|}{ Post-test } \\
\hline & Frequency & Percentage & Frequency & Percentage \\
\hline Inadequate & 31 & 62.0 & 0 & 0 \\
\hline Moderately adequate & 19 & 38.0 & 21 & 42.0 \\
\hline Adequate & 0 & 0 & 29 & 58.0 \\
\hline
\end{tabular}

The result revealed that In Pre-test, majority $31(62.0 \%)$ of them had inadequate knowledge, 19 (38.0\%) had moderately adequate knowledge and none of them had adequate knowledge where as in post-test maximum number of them $29(58.0 \%)$ had adequate knowledge, $21(42.0 \%)$ of them had moderately adequate knowledge and none of them had inadequate knowledge. Hence, research hypothesis $\left(\mathrm{H}_{1}\right)$ was accepted.

Finding related to association between posttest knowledge score of ANM students with their Sociodemographic variables.

The association between demographic variables and posttest knowledge score regarding suicidal prevention revealed that age and occupation of parents were found to be statistically significant where as domiciliary area ,religion, type of family, education of students, source of information and Annual family income were found to be non-significant.

\section{Discussion:-}

The present study revealed that In Pre-test, majority 31 (62.0\%) of them had inadequate knowledge, 19 (38.0\%) had moderately adequate knowledge and none of them had adequate knowledge where as in post-test maximum number of them $29(58.0 \%)$ had adequate knowledge, $21(42.0 \%)$ of them had moderately adequate knowledge and none of them had inadequate knowledge. It is supported by a study conducted by Mr.Veeresh kumar Nandagaon to assess the effectiveness on knowledge regarding the suicidal prevention among nursing students. The majority during the pre-test $09(15 \%)$ of the subjects had poor knowledge level, $42(70 \%)$ of the subjects had average knowledge level and $09(15 \%)$ of the subject had good knowledge on suicidal behavior. After the introduction of STP in the post test there was significant increase in the knowledge scores. Out of 60 people 59(98\%) belong to good knowledge 01 (02\%) belong to average knowledge level. Results showed that STP was effective methods to improve the knowledge. ${ }^{5}$

\section{Conclusion:-}

The overall findings of the study clearly showed that knowledge level was increased in the group after intervention. Hence there is a need for conducting interventional studies among nursing students so that their knowledge can be enhanced through various studies, as frequent reinforcement increases the knowledge level of the subjects, this was proved through this study. 


\section{Acknowledgement:-}

Author is thankful to Management, faculty and ANM Students of Royal institute of Nursing, Jaito Sarja, Batala to carry this research project.

\section{References:-}

1. https://en.wikipedia.org/wiki/Suicide.

2. http://www.mayoclinic.org/diseases-conditions/suicide/basics/symptoms/

3. Vijaya kumar, L Kumar. Substance use and suicide. Current opinion in psychiatry. May 2011.Page no: 197202.

4. WHO. Worldwide suicide information; Figures and facts about suicide. 2004. Available from http://www.suicideandmentalheathassociationinternational.org.

5. R Shreevani. Evaluate the effectiveness of planned teaching programme on suicidal prevention among undergraduate studensts.3rd edition. Jay pee publications .July 2014.Page no.13. 